\title{
Are Momentum Traders Different? Implications for the Momentum Puzzle
}

\author{
Lukas Menkhoff \\ Discussion Paper No.448 \\ May 2010 \\ ISSN 0409-9962
}

\begin{abstract}
This paper examines the puzzlingly high unexploited momentum returns from a new perspective. We analyze characteristics of momentum traders in a sample of 692 fund managers. We find that momentum traders are "defined" by their short-term horizon, by a behavioural view on the market and by a somewhat lower degree of risk aversion, whereas they are like other fund managers with respect to sophistication. This is consistent with the interpretation that momentum returns may compensate for the risk of momentum trading on short-term horizons and that the short-term oriented momentum traders are not in a position to perform long-term arbitrage.
\end{abstract}

JEL-Classification: G 14 (information), G 23 (fund management) D 85 (speculations) Keywords: momentum trading, market efficiency, behavioural finance, risk

I would like to thank the responding fund managers for their participation in this study and an anonymous referee for stimulating comments. Moreover, I thank the investment management associations of Germany, Italy and Thailand as well as Daniela Beckmann, Torben Lütje, Michael Melvin and Luca Rebeggiani for their most generous support in conducting the survey study. Helpful research assistance was provided by Fabian Bätje and Oliver Gloede. Financial support by the Volkswagen Foundation is gratefully acknowledged.

Lukas Menkhoff, Department of Economics, Leibniz Universität Hannover, Königsworther Platz 1, D-30167 Hannover, Germany, e-mail: menkhoff@gif.uni-hannover.de, tel.: +49-511-762-4551, fax: +49-511-762-4796 


\section{Are Momentum Traders Different? Implications for the Momentum Puzzle}

\section{Introduction}

The application of momentum strategies in financial markets yields excess returns, i.e. returns which cannot be easily explained on the basis of established capital market models, such as the Capital Asset Pricing Model (CAPM) (Jegadeesh and Titman, 2001). Accordingly, one expects, and it is true that investors use, momentum strategies in order to realize riskadjusted profits (e.g. Grinblatt et al., 1995, Badrinath and Wahal, 2002, Mulvey and Kim, 2008). This seems very tempting as momentum trading is extremely simple to implement: investors just buy past winners and-if short selling is feasible-sell past losers. If enough investors consistently follow this strategy the excess returns will disappear due to an arbitrage process. We know, however, that momentum excess returns are still there, which provides a serious puzzle to our understanding of financial markets, known as the "momentum puzzle": how is it possible that momentum excess returns can be earned (and investors do not consistently realize them) ${ }^{1}$

Answers to this puzzle can be grouped into three views: first, the- - somewhat narrowly interpreted-efficient market view implies that momentum returns only seemingly exist; second, the behavioural finance view implies that behavioural influences on prices contribute to explaining the momentum puzzle and third, the risk aversion view focuses on so far poorly understood risks inherent to momentum trading. There is evidence supporting each of these views, but it seems fair to conclude that the puzzle is far from being solved (see e.g. Li et al., 2008). Therefore, we contribute to the literature by complementing existing time-series studies with a "framed field experiment" (Harrison and List, 2004): we analyze a cross-section of fund managers, testing whether momentum traders are different from other fund managers (we use this term interchangeably with "asset manager"). We find, indeed, interesting characteristics of momentum users which shed light on the three above-mentioned views of the momentum puzzle. Most importantly, evidence suggests that momentum traders are-due to their very shortterm orientation-not in the best position to implement successful long-term arbitrage strategies which could eliminate the momentum puzzle.

In order to get the necessary information about fund managers, their thinking and their behaviour, we have conducted a questionnaire survey study among fund managers in the U.S., 
Germany, Switzerland, Italy and Thailand. ${ }^{2}$ The coverage of several countries seems to be of particular interest as it has been argued that the existence and level of momentum returns is affected by cultural factors (Chui et al., 2010). However, our interest is not in the crosscountry variation but - quite the opposite-in those questionnaire items that characterize momentum traders in general. Accordingly, we derive testable implications from the three views, confront them with our survey data and see whether they receive unanimous support in several countries.

Among the three views tested with our survey data, the behavioural view enjoys clear support and the risk view receives some support, whereas the efficient market view gets no support at all. We find that momentum traders tend to share a common view about financial markets in that they give behavioural factors a greater importance than other fund managers do. Moreover, they seem to share a quite short-term perspective when making investment decisions. These two elements-behavioural forces and short-term perspective-are well-known from technical traders in general, which is of course no surprise, as momentum trading belongs to the larger group of technical trading strategies (Menkhoff and Taylor, 2007). ${ }^{3}$ However, momentum traders differ from average technical traders in that they place less emphasis on behavioural forces and more on short-term horizons.

It thus seems interesting to note that momentum traders differ neither from other technicians nor from all other fund managers with respect to their sophistication and degree of overconfidence. Accordingly, the suspicion of the efficient market view that momentum traders might simply be less sophisticated fund managers who falsely follow an irrational trading strategy cannot be substantiated by our data. Interestingly, our finding also excludes the opposite possibility, that momentum traders might be particularly clever, acting in advance of the regular fund managers.

Finally, momentum traders show behaviour towards risk that is partially different from others. So there is some evidence that momentum traders might be willing to bear higher risk, which might explain the high momentum returns as compensation for such risk. However, consistency and levels of significance are limited, so that this risk aversion view is only tentatively supported by our results.

\footnotetext{
${ }^{1}$ Brown et al. (1998) show that the Dow theory prominently published in the early $20^{\text {th }}$ century can be understood as a momentum strategy. So, momentum returns have been debated for a long time and they exist in many countries (Rouwenhorst, 1998).

${ }^{2}$ Questionnaire surveys are a standard tool in social sciences to get information which is not available from other sources. Prominent studies in financial economics include Taylor and Allen (1992), Welch (2000), Graham and Harvey (2001) and Brav et al. (2005).

3 Technical trading encompasses various forms including "chartism" and "relative strength indicators". The latter may be seen as a more conventional form of momentum trading.
} 
In the following Section 2 we will detail the three views given in the literature. Almost all of these studies analyze the time-series. To the best of our knowledge, there is only the study by Menkhoff and Schmidt (2005), which is similar to ours in its cross-sectional approach because they have related German fund managers' characteristics to their preferred trading strategy, including momentum trading. This work can be seen as the pilot study to ours because we conduct a multi-country study (also covering more than twice as many fund managers in Germany) and consider a broader set of items-only these extensions allow a systematic test of the three views introduced. ${ }^{4}$

We proceed as follows: Section 2 introduces the literature and develops testable hypotheses. Section 3 describes the survey and Section 4 presents the use of momentum trading. Results on testing the three hypotheses are discussed in Sections 5 to 7, covering the efficient market view, the behavioural finance view and the risk aversion view, respectively. Section 8 concludes.

\section{Hypotheses}

This section derives the hypotheses to be tested in this study from earlier literature on the momentum puzzle.

Regarding the efficient market view, there are arguments that momentum returns might be due to a bias in selecting assets with high returns (Conrad and Kaul, 1998), or due to an underestimation of transaction costs (Korajczyk and Sadka, 2004, see Bikker et al., 2010). The argument of "asset selection" has not been confirmed in later studies (Jegadeesh and Titman, 2001). Unlike that, "transaction costs" are indeed higher in small stocks with particularly high momentum returns but costs are not high enough to erase excess returns. Going beyond these arguments, the efficient market hypothesis (Fama, 1970) argues that users of technical analysis may be less sophisticated than others. Although this suspicion has not been supported in research on technicians in general (Gehrig and Menkhoff, 2006, Menkhoff and Taylor, 2007), it is still possible that it applies to momentum traders in particular. Following this argument, unsophisticated investors apply momentum trading, which only seemingly provides advantages (but in effect has disadvantages being so far unobserved). Thus we test whether momentum traders are less characterized by indicators of sophistication than others. Logically, one can also put forward a reverse argument: momentum trading may be related to sophistication,

\footnotetext{
${ }^{4}$ Hvidkjaer (2006) also analyzes momentum in a cross-section-distinguishing small and large trades - and shows that "momentum could partly be driven by the behaviour of small traders". This raises the question why large investors, such as fund managers, do not trade more heavily against this distortion.
} 
if there are obstacles to the use of momentum trading and if it requires a high degree of investor sophistication to overcome these obstacles. Accordingly, we let the data speak for itself and see whether indicators of investor sophistication are related to the use of momentum strategies.

The analytical research on users of technical analysis has found that technicians have a unique understanding of financial markets which is built up in particular by a strong reference to psychological forces. In short, one may call this a behaviourally-inspired market view, i.e. a behavioural finance view (e.g. Hirshleifer, 2001, Shiller, 2003). This view also receives credibility from experimental studies finding that many participants form positive feedback expectations (e.g. Hommes et al., 2008). This expectation formation in turn is then often used as a building block in studies with heterogeneous agents simulating market outcomes that resemble real world stylized facts (e.g. Lux, 1998, Manzan and Westerhoff, 2007, Bask, 2009). So it seems plausible that momentum traders refer to behavioural forces as price determinants and consequently rely more on information sources which may be helpful in understanding such behavioural influences. ${ }^{5}$ A second robust finding in the literature on technical analysis is its relation to a shorter forecasting horizon (see early Taylor and Allen, 1992). The horizon of the users of technical analysis is not extremely short, a fact which rather applies to users of flow analysis, but it is clearly shorter than the horizon of fundamentalists (Menkhoff and Taylor, 2007). Thus, our guiding hypothesis is again that, with respect to their shorter forecasting horizon, momentum traders will be similar to technical traders in general. In contrast to traders, however, fund managers act on behalf of their customers, so that the "behavioural distortion" of a short-term horizon may be caused by either their own preferences or those of their customers. In the latter case, fund managers may rationally react on their incentives.

Finally, most research on explaining momentum strategies has focused on revealing so far unconsidered risk factors of momentum trading which go beyond the CAPM and the three factor model of Fama and French (1993) — the risk aversion view. However, there is no evidence of particular risk in the form of a macro factor or dependence on market states (Grundy and Martin, 2001, Chordia and Shivakumar, 2002, Griffin et al., 2003). The missing evidence however, does not necessarily exclude the possibility that momentum returns are caused by so far unobserved risk factors which users must be able to stand. Seen from the perspective of fund managers, a lower degree of risk aversion would then be a prerequisite for the successful

\footnotetext{
5 There are indeed studies arguing that momentum may be caused by behavioural "distortions", such as Hong and Stein (1999) or Jegadeesh and Titman (2001); see also Barberis et al. (1998) and Daniel et al. (1998). Hvidkjaer (2006) shows that smaller trades, representing smaller investors, behave in a way
} 
use of momentum strategies. Beyond the general degree of risk aversion it has been argued that momentum trading may require bearing particular aspects of risk, such as downside risk (Ang et al., 2006) or myopic loss aversion (Menkhoff and Schmeling, 2006). ${ }^{6}$ Indeed, these studies claim that risk-adjusted returns of momentum strategies would considerably decrease by measuring risk beyond its conventional symmetrical form. ${ }^{7}$ Consequently, momentum traders may be investors who are better able to withstand risk in general or in particular forms, a topic which we address by respective items in our questionnaire.

Overall, we get a set of hypotheses which is testable by way of a questionnaire and whose results have implications for the relevance of the three main views on the momentum puzzle.

\section{Survey}

Critical requirements on useful surveys are their representativeness and reliability. We show in this section what has been done to fulfil these requirements.

Regarding representativeness, it would be ideal to get responses from relevant fund managers all over the world. In fact, however, fund managers are very busy and are inundated by requests from research institutions and others to fill in questionnaires, give interviews, etc. The simple sending out of questionnaires would result in disappointingly low response rates and thus easily distorted samples. So a sizeable amount of effort has to be invested and with limited resources available, one needs to make a decision on the selection of countries. (1) In asset management, there is no question that the United States should be part of the survey. (2) Then, a Continental European market seems desirable to ensure participation from a capital market-based financial system, i.e. the US, and a bank-based financial system. (3) Finally, the study's scope would profit from the participation of an emerging market. Within the groups of Continental Europe and emerging markets, we have invested effort in winning support from respected national investment associations and were successful in three cases, i.e. Germany, Italy and Thailand. We also asked the respective association in France, but in vain; we won support in Singapore but the outcome was disappointing (compared to market size). Therefore, our country coverage is both intentional and accidental. There is no reason to believe, how-

consistent with creating momentum; these investors may be plagued by "biased expectations", contrasting with more professional large investors.

${ }^{6}$ Myopic loss aversion seems to be conceptually (Benartzi and Thaler, 1995) as well as empirically (Haigh and List, 2005) important.

${ }^{7}$ Further studies link momentum returns to liquidity risk (Sadka, 1996) and time-varying unsystematic risk (Li et al., 2008). 
ever, that for example the inclusion of France and Singapore-as substitutes for Germany and Thailand—would yield different results.

Accepting the selection of five markets, we always present empirical evidence separately for each country. This avoids a possible dominance of the combined sample by one or several countries. It also avoids a discussion about possible weighting of countries. Finally, due to our treatment, the country cases are independent observations so that they can be seen as several tests in one paper, or one may regard the U.S. as benchmark and the other four countries as out-of-sample cases.

When aiming for representativeness it is desirable to win responses from all relevant fund managers in these markets. So we requested answers from a representative share of fund managers simply by addressing the head of fund management and mostly asking for a response of from two to six questionnaires, depending on firm size. This ensures that larger firms receive a higher "weight" in the sample, which might be important if fund managers' behaviour is related to firm size. Table 1 shows that we have received 692 responses in total and that larger firms indeed have a systematically higher weight in the survey (see last row in Table 1). The resulting response rate of fund management firms is between 29 per cent in Switzerland and 94 per cent in Thailand. These figures are reasonable when compared to similarly designed studies, such as Graham and Harvey (2001) or Menkhoff and Schmidt (2005). ${ }^{8}$

Assuming that there are responses at all, a further goal is attaining responses from those persons who carry the responsibility for decisions in fund management, i.e. senior fund managers, and not just junior or support staff. The outcome in this respect is favourable, as the structure of respondents in Table 2 shows: fund managers' positions are mostly senior, as supported by evidence about their age and experience.

The contribution of senior fund managers to the survey is a clear indication of its usefulness as these persons spent their valuable time in responding. In preparing the survey, we took the following measures: first, we obtained supporting letters from fund management apex organizations in Germany, Italy and Thailand. Second, in each country we conducted several indepth interviews with fund managers to find out the most appropriate wording and to prepare appropriate translations. ${ }^{9}$ Third, we conducted test runs to check understanding and practicability. Overall, effort was taken to ensure the right "properties of the situation" (Levitt and

\footnotetext{
${ }^{8}$ The international survey underlying this research is the basis of a larger research project and has been used in other directions as well. Beckmann et al. (2008), for example, examine cultural differences between fund managers.

${ }^{9}$ The language of the survey was English in the U.S. and Thailand, German in Germany, German and French in Switzerland and Italian in Italy. Critical passages of the questionnaire have been translated forward and backward to ensure a consistent wording.
} 
List, 2007). This is crucial for yielding the results from this "framed field experiment" which are relevant to real world behaviour (Harrison and List, 2004).

Another important aspect of reliability is anonymity. Some fund managers did not worry about this and gave their names in one way or another when sending their completed questionnaires by mail, fax or email, but most preferred to stay anonymous, although firm identification was available in almost all cases. A measure to aid anonymity was to ask for personal information in categories, such as an age category between 30 and 35 years, etc.

Finally, one might question reliability of answers because we analyze fund managers' "normal investment strategies", as if they depended on their personal preferences. In reality, however, investment strategies are typically formulated in or guided by investment committees, so that the practiced strategies also depend on the preferences of the asset management firm and of the respective customer. However, we have learned in the interviews preparing the survey that fund managers do have some influence on investment strategy. We are indeed interested in their individual perspective, which is made explicit at the top of each questionnaire, stating that this is "an academic research project which focuses on the personal [emphasized here] viewpoints, perceptions and investment behavior of professional asset managers".

Due to these measures we are confident that responses are largely representative and reliable.

\section{The use of momentum trading}

We add to the literature by providing more detailed information on the widespread use of momentum trading: most fund managers in each country of our survey use it to some degree, and a strong minority of between 25 and 50 per cent uses it as a major or even the major investment strategy.

Due to various studies analyzing institutional investments, we know that most mutual funds in the U.S. practice some form of momentum trading (Grinblatt et al., 1995) and that U.S. institutional investors in general rely on this strategy (e.g. Keim and Madhavan, 1995, Badrinath and Wahal, 2002). So there is no question that momentum trading is important among U.S. fund managers and-due to financial globalization-among fund managers in other countries as well. We do not really know, however, how important it is in relation to alternative strategies.

Therefore, our survey asks the fund managers: "Which strategies are your investment decisions normally based upon?" and names five strategies, i.e. momentum, contrarian, buyand-hold, dividend-oriented and other. Fund managers allocate 100 per cent to these five alter- 
natives. The universe of investment strategies is classified into these five groups according to the preceding interviews with fund managers. An indication of appropriateness and clarity of this classification is the fact that only a small share of the total 100 per cent is allocated to all "other strategies"; it ranges in the five countries between 2 and 23 per cent only.

Among the strategies, it may be expected that buy-and-hold receives the highest percentage as it reflects either passive investments or a close benchmark orientation. Indeed, the unweighted average of the five countries with respect to the buy-and-hold strategy is about 30 per cent. It is thus interesting that momentum strategies rank third with an average of about 23 per cent, with a range between 17.5 in the U.S. and 26.6 in Germany. These mean values for momentum strategies are shown as first bar for each country in Figure 1.

The country mean values, however, cover quite some heterogeneity among fund managers within each country. When we analyze the share of fund managers that uses momentum trading at all, i.e. gives it a weight of greater than zero, this share is 57 per cent in the U.S. and above 80 per cent in the other four countries with a maximum of 87 per cent in Thailand (see the second bar for each country in Figure 1). This result matches the notion that most fund managers practice some momentum trading, as found by Grinblatt et al. (1995). However, the use of momentum trading to some degree does not indicate whether it is really important. Accordingly, Figure 1 gives the share of fund managers practicing this strategy at increasing minimum levels of 20 per cent (third bar) and of 30 per cent (fourth bar) and for the share of fund managers who prefer this strategy unanimously to alternatives (fifth bar).

Whereas there are large groups in all markets which use momentum trading by as much as 20 or even 30 per cent, fund managers unanimously preferring momentum trading are rare, composing a share of about 12 per cent. Obviously, this latter criterion of a preference for momentum trading is somewhat harsh, because weights are distributed among five categories and we define "a preference" as giving momentum trading a higher weight than to every other category plus a minimum level of 40 per cent. Due to this definition, we exclude cases such as 50 per cent on momentum trading but also 50 per cent on another strategy and we also exclude fund managers who distribute for example 35 per cent on momentum trading and 25-25-15 per cent on other categories.

As this narrow definition would result in small absolute numbers of momentum traders in our country samples, in the following analyses we decide to compare those fund managers who allocate at least 30 per cent on the momentum strategies to all others (even if those others allocate up to 29 per cent to momentum trading). This definition identifies between 25 and 51 per cent of fund managers as momentum traders (depending on the country) and distinguishes 
them from others. The momentum trader share is lowest in the U.S. with 25.2 per cent, followed by Switzerland with 26.6 per cent, Thailand with 27.4 per cent, Italy with 42.5 per cent and is highest in Germany with 50.6 per cent (see fourth bar in Figure 1).

In robustness tests we have used different definitions: (1) we have compared fund managers preferring momentum trading (see definition in Figure 1) to others, (2) we have compared our definition of momentum traders to those fund managers giving it a weight of less than 20 per cent (this analysis sharpens the distinction by excluding all fund managers giving momentum trading a weight of between 20 and 29 per cent) and (3) we have analyzed rank correlations between the degree of momentum trading and items of interest. Whatever definition and procedure we use, results are qualitatively robust to these variations. Thus, we stick to our simple and straightforward definition.

Overall, most fund managers use momentum strategies to some degree and a large share in each country-ranging from 25 to 51 per cent-is made up of heavy users of momentum trading, who give it a weight of at least 30 per cent. This group of momentum traders is compared to the remaining fund managers in the following part. We perform this comparison country by country to see whether findings are robust.

\section{$5 \quad$ The efficient market view on momentum traders}

The efficient market view suggests that momentum traders, like other traders relying on technical analysis, may be less sophisticated (because technical trading will produce only transaction costs without gains in efficient markets). This view is not supported by our data.

In the following, we compare characteristics of fund managers-which indicate their degree of sophistication-between the two groups introduced above (see Section 4), i.e. momentum traders and other fund managers. As indicators of sophistication, we rely on personal characteristics as well as on items informing about overconfidence in decision making.

Personal characteristics of fund managers that can serve as useful proxies of sophistication are chosen in line with earlier studies (see Gehrig and Menkhoff, 2006). Respective hypotheses state that increasing age and increasing professional experience in asset management indicate some competence in competitive markets and thus sophistication. Less sophisticated fund managers would be tentatively eliminated over time. Further hypotheses state that a better education supports more sophisticated behaviour, a premise also underlined, as one would expect, by the fact that fund managers holding superior positions and having personal responsibility for larger assets under management have shown ability. Finally, we consider in this respect the size of the firm where the fund managers are employed (proxied by total assets un- 
der management), because large firms have more capacity for research and thus have less need to rely on simple trading rules such as a momentum strategy.

Results from these six items are presented in Table 3. One can directly ascertain from the missing significant differences between the two groups that momentum traders are not systematically less sophisticated than fund managers who prefer other forms of investment strategies. There are a few cases of significant differences: momentum traders are a little younger in Thailand and hold somewhat inferior positions, whereas in Germany they work in smaller firms. However, these are 3 cases out of 30 and the significance level in 2 of these 3 cases is just ten per cent.

Coming to the second approach, which reveals a possible lack of sophistication, we analyze the relation between overconfidence and momentum trading (see Daniel et al., 1998). In detail, Glaser and Weber (2007) suggest using three indicators of overconfidence. Menkhoff et al. (2006) apply these indicators to fund managers in Germany. In order to keep the survey short, they choose one questionnaire item for each of the three indicators and find a clear tendency towards overconfidence. Here, however, we are not interested in the absolute level of overconfidence but in its relative level between momentum traders and others. The three measures of overconfidence are unrealistically positive self-evaluation, illusion of control and miscalibration. The concrete items used to evaluate overconfidence are similar to Menkhoff et al. (2006). Self-evaluation is grasped by self-assessment of one's own achievements in relation to other comparable fund managers (see item 1 in Table 4), the illusion of control is proxied by the statement that news does not surprise (item 2) and miscalibration is measured by the expected-i.e. one month ahead- $90 \%$ confidence intervals of two stock market indices (item $3)$.

Results are given in Table 4. A look at the significance of differences shows that there is not much to reveal. To cut a long story short, momentum traders are not different from others with respect to overconfidence, indicating that this is no plausible motivation for using momentum strategies. ${ }^{10}$ This unanimous finding may justify once more the few items used to analyze overconfidence.

Overall, the efficient market view is not supported by the proxies used in our survey study. It may be reassuring that this result matches the more general analysis of technical traders. We now turn to the second view, the behavioural finance perspective.

\footnotetext{
${ }^{10}$ Both groups of fund managers seem to show some overconfidence as the lowest value of selfassessment reached is 3.25 for momentum traders in Germany (compared to a neutral value of 4), the average answer on the level of surprise is between 2.89 and 3.50 whereas true surprise would be between 4 and 6 and, finally, the $90 \%$ confidence intervals are too narrow.
} 


\section{The behavioural finance view on momentum traders}

This section shows that the behavioural finance view on momentum traders earns support, but with a remarkable difference compared to technicians in general: momentum traders are less characterized by their psychological perspective on financial markets but very heavily by their short-termism.

The behavioural finance view suggests that financial markets are influenced by behavioural patterns inconsistent with conventional capital market theories (Hirshleifer, 2001). A most general statement in this respect asks about the relative importance of psychological influences versus fundamentals. The relation between psychological influences and the use of technical analysis was established by Taylor and Allen (1992) and has been confirmed in several studies since then (see Menkhoff and Taylor, 2007). It seems thus consistent that momentum traders share this view. More specific but also prominent issues are the importance of herding and a confirmation bias in financial markets. Both characteristics seem to be supportive of momentum trading because these forms of behaviour may be responsible for the formation or continuation of non-fundamental trends in asset prices (e.g. Lütje, 2009).

The respective questionnaire items as well as the responses are presented in Table 5. The level of agreement in all groups is 3.36 or smaller (on a scale between 1 for strong agreement and 6 for strong disagreement). Thus it indicates that most fund managers share to some degree the notion that psychological influences can be important. Accordingly, herding and miscalibration receive rather supportive answers-values lower than the mean of 3.5 signal support. Even the strong statement that psychological influences are more important than fundamentals receives responses below the critical value 3.5 and thus support. In most cases we also recognize that momentum traders have lower values than others and in some cases these differences are significant. Overall, the psychological perspective on financial markets is widely shared among momentum traders, perceptibly more than among fund managers in general. Accordingly, it seems rational that believers in momentum trading do not solely rely on fundamental analysis to understand financial markets but also on technical analysis (see Menkhoff and Taylor (2007).

Another feature of interest concerning users of technical analysis in general-and thus probably about momentum traders too-is the observation that they tend towards short-term horizons, as shown at an early stage by Taylor and Allen (1992) for foreign exchange traders. A perception of the relation between technical analysis, psychological influences and short horizon seems to be that psychological forces may be more relevant at shorter horizons 
whereas in the long run, fundamentals will dominate (e.g. Taylor and Allen, 1992). However, it also seems possible that short-term horizons are determined by incentives and that fund managers rationally respond to these incentives. In the first place, firms implement such incentives, for example by rewarding short-term performance, but in the end it will be customers who influence these incentives. We examine this issue in more detail.

A general question asks about the forecasting horizon in investment decisions and we will learn whether momentum traders differ in this respect from other fund managers. Regarding the deeper motivation for short-term orientation, two questions address either the behavioural view of the market or incentives set by customer behaviour (whose short-termism can be behaviourally determined). Accordingly, short-term oriented fund managers may behave as trend followers or they may refer to client expectations.

The three exact questionnaire items as well as fund managers' responses are given in Table 6. It is the first time in this research that momentum traders differ from others in the same direction in all three items in all five countries: they are more short-term oriented. This difference is statistically significant in 11 of 15 cases. In order to demonstrate this strong relation with respect to the full distribution we graphically relate the average reliance on momentum strategies to the five categories of forecasting horizons-each country is considered separately and thus gets its own line in Figure 2. This figure underlines the strong relation between momentum trading and short-term horizon. Regarding a deeper motivation for this shorttermism, both "trend following" and "client pressure" are highly significantly related to momentum trading. This indicates that both motivations may be important, i.e. a behavioural view of the market by fund managers and incentives set by customers who may be behaviourally influenced. Finally, incentives set by the firm might play a role but we do not find an obvious relation between momentum trading and various kinds of performance-based remuneration systems (presented in Appendix 1).

In summary, the behavioural finance view on momentum traders is clearly confirmed by the data. Interestingly, when compared to technical traders in general, momentum traders rely somewhat less on psychological influences but even more on a short-term perspective. The latter is so strong that it can be regarded a defining characteristic.

\section{$7 \quad$ The risk aversion view on momentum traders}

A low risk aversion of momentum traders could indicate that they are willing and able to bear high risks which may be inherent in this strategy (and might "explain" necessary high 
returns to compensate for risk). We do indeed find evidence that momentum traders are different in some aspects of their risk aversion.

The conventional interpretation of momentum excess returns is that they compensate for a kind of risk which is not captured by standard asset pricing models. However, this risk would be real and investors would have to bear it, so it seems interesting to see whether momentum traders may be less risk averse than others (see Menkhoff and Schmidt, 2005). We offer in this respect a standard bet to reveal general risk aversion and we also investigate the self-assessment regarding risk-taking in investment decisions. Interestingly, riskiness of momentum trading has not only been put forward from a conventional capital market perspective but also from a behavioural finance perspective. Accordingly, we investigate respective measures of riskiness which include loss aversion and the disposition effect. Loss aversion considers an asymmetry in riskiness of investments which is neglected in conventional theory and which may be costly for investors (see Odean, 1998). The disposition effect-selling winners too early and holding losers too long (Shefrin and Statman, 1987)—considers a disposition going beyond loss aversion and which is also known to be costly for investors.

As in earlier sections, Table 7 covers the exact questionnaire items and results. Results show few differences between momentum traders and others in the expected direction. Regarding conventional risk measures, the lottery does not reveal a difference, but self-stated willingness to take risk in investment decisions is significantly higher for momentum traders in the U.S. and Switzerland. Regarding behavioural risk concepts, loss aversion of momentum traders is slightly lower for momentum traders in the U.S. and Thailand, whereas the disposition effect is not systematically related to momentum trading because the two significant differences - in the U.S. and Germany each—have opposite coefficient signs.

Overall, the risk aversion view contributes to our understanding of the momentum puzzle as it cautiously indicates that momentum traders may be willing to bear higher risks, here seen as investment risks and with respect to loss aversion.

\section{Conclusion}

This research addresses one of the important puzzles in finance: why do investors not realize excess returns from momentum trading (so that returns go down to a "normal" level)? We complement the wealth of time-series studies with a new approach in this field, i.e. a framed field experiment, in that we study the cross-section of momentum traders. We find that they are different from other fund managers and that these differences shed light on the explanatory power of competing views on the momentum puzzle. 
Our main finding is the very close relation between a behavioural view of the market and short-term horizons with momentum trading. This finding is confirmed by a Probit model where we include as explanatory variables those six items that have been statistically significant in at least two countries during the earlier analyses (see Table 8). Results are qualitatively unaffected by including firm dummies into this regression which might capture firm-specific effects (see Appendix 2). Results are also robust to the inclusion of further items (not shown here). A plausible interpretation of our main finding suggests that momentum traders have a behavioural view which leads-in combination with a long-term trend towards fundamentals-to short forecasting horizons. Alternatively, short-term horizons may result from customer preferences. Then momentum traders rationally react to this demand of short-termism by preferring strategies which perform better at short horizons. However, are momentum strategies really superior at short horizons? Available evidence shows superiority at long horizons but rather volatile returns at short horizons (Menkhoff and Schmeling, 2006). Moreover, following this interpretation does not make it clear why the customers demand short horizons; possibly, they are plagued by behavioural distortions. In summary, this supports a behavioural finance view on the momentum puzzle which is enforced by customers' short-term performance pressure.

Our second finding is that momentum traders seem to be somewhat less risk averse than others. Evidence is not very strong in this respect but it holds in particular for investment specific risk aversion. This supports the risk view on the momentum puzzle. As a third finding, we show that momentum traders are as sophisticated as others, which does not conform to the narrow efficient market view.

Overall, these findings suggest an interpretation not easily consistent with efficient markets. Accordingly, momentum strategies are risky over shorter horizons, a fact which is not well addressed by conventional approaches. Those fund managers who are willing to bear this risk in order to earn high momentum returns are, however, exactly the same fund managers who are characterized by short-term horizons. Thus, they realize a high return and high risk investment but they do not follow a longer-term strategy which might be able to earn excess returns. This interpretation is of course somewhat speculative and the survey approach is explorative. However, if this interpretation is true, the present situation may describe an unpleasant "equilibrium" and the momentum puzzle may continue for some time. 


\section{References}

Ang, A., Chen, J. and Xing, Y. (2006) Downside risk, Review of Financial Studies, 19, 11911239.

Badrinath, S.G. and Wahal, S. (2002) Momentum trading by institutions, Journal of Finance, 57, 2449-2478.

Barberis, N., Shleifer, A. and Vishny, R. (1998) A model of investor sentiment, Journal of Financial Economics, 49, 307-343.

Bask, M. (2009) Announcement effects on exchange rates, International Journal of Finance and Economics, 14, 64-84.

Beckmann, D., Menkhoff, L. and Suto, M. (2008) Does culture influence asset managers' views and behavior?, Journal of Economic Behavior and Organization, 67, 624-643.

Benartzi, S. and Thaler, R.H. (1995) Myopic loss aversion and the equity premium puzzle, Quarterly Journal of Economics, 110, 75-92.

Bikker, J.A., Spierdilk, L. and van der Sluis, P.-J. (2010) What factors increase the risk of incurring high market impact costs?, Applied Economics, 42, 369-387.

Brav, A., Graham, J.R., Harvey, C.R. and Michaely, R. (2005) Payout policy in the 21st century, Journal of Financial Economics, 77, 483-527.

Brown, S.J., Goetzmann, W.N. and Kumar, A. (1998) The Dow theory: William Peter Hamilton's track record reconsidered, Journal of Finance, 53, 1311-1333.

Chordia, T. and Shivakumar, L. (2002) Momentum, business cycle, and time-varying expected returns, Journal of Finance, 57, 985-1019.

Chui, A.C.W., Titman, S. and Wei, K.C.J. (2010) Individualism and momentum around the world, Journal of Finance, 65, 361-392.

Conrad, J.S. and Kaul, G. (1998) An anatomy of trading strategies, Review of Financial Studies, 11, 489-519.

Daniel, K., Hirshleifer, D. and Subrahmanyam, A. (1998) Investor psychology and security market under- and overreactions, Journal of Finance, 53, 1839-1885.

Fama, E.F. (1970) Efficient capital markets: a review of theory and empirical work, Journal of Finance, 25, 383-417.

Fama, E.F. and French, K.R. (1993) Common risk factors in the returns on stocks and bonds, Journal of Financial Economics, 33, 3-56.

Gehrig, T. and Menkhoff, L. (2006) Extended evidence on the use of technical analysis in foreign exchange, International Journal of Finance and Economics, 11, 327-338.

Glaser, M. and Weber, M. (2007) Overconfidence and trading volume, Geneva Risk and Insurance Review, 32, 1-37.

Graham, J.R. and Harvey, C.R. (2001) The theory and practice of corporate finance: evidence from the field, Journal of Financial Economics, 60, 187-243.

Griffin, J.M., Ji, S. and Martin, J.S. (2003) Momentum investing and business cycle risk: evidence from pole to pole, Journal of Finance, 58, 2515-2547.

Grinblatt, M., Titman, S. and Wermers, R. (1995) Momentum investment strategies, portfolio performance, and herding: a study of mutual fund behavior, American Economic Review, 85, 1088-1105.

Grundy, B.D. and Martin, J.S. (2001) Understanding the nature of the risks and the source of the rewards to momentum investing, Review of Financial Studies, 14, 29-78.

Haigh, M.S. and List, J.A. (2005) Do professional traders exhibit myopic loss aversion? An experimental analysis, Journal of Finance, 60, 523-534.

Harrison, G.W. and List, J.A. (2004) Field experiments, Journal of Economic Literature, 42, 1009-1055.

Hirshleifer, D. (2001) Investor psychology and asset pricing, Journal of Finance, 56, 15331597. 
Hommes, C., Sonnemans, J., Tuinstra, J. and van de Velden, H. (2008) Expectations and bubbles in asset pricing experiments, Journal of Economic Behavior and Organization, 67, 116-133.

Hong, H. and Stein, J. (1999) A unified theory of underreaction, momentum trading and overreaction in asset markets, Journal of Finance, 54, 2143-218.

Hvidkjaer, S. (2006) A trade-based analysis of momentum, Review of Financial Studies, 19, 457-491.

Jegadeesh, N. and Titman, S. (2001) Profitability of momentum strategies: an evaluation of alternative explanations, Journal of Finance, 56, 699-720.

Keim, D.B. and Madhavan, A. (1995) Anatomy of the trading process, empirical evidence on the behavior of institutional traders, Journal of Financial Economics, 37, 371-398.

Korajczyk, R.A. and Sadka, R. (2004) Are momentum profits robust to trading costs? Journal of Finance, 59, 1039-1082.

Levitt, S.D. and List, J.A. (2007) On the generalizability of lab behaviour to the field, Canadian Journal of Economics, 40, 347-370.

Li, X., Miffre, J., Brooks, C. and O'Sullivan, N. (2008) Momentum profits and time-varying unsystematic risk, Journal of Banking and Finance, 32, 541-558.

Lütje, T. (2009) To be good or to be better: asset managers' attitudes towards herding, Applied Financial Economics, 19, 825-839.

Lux, T. (1998) The socio-economic dynamics of speculative markets: interacting agents, chaos, and the fat tails of return distributions, Journal of Economic Behavior and Organization, 33, 143-165.

Manzan, S. and Westerhoff, F.H. (2007) Heterogeneous expectations, exchange rate dynamics and predictability, Journal of Economic Behavior and Organization, 64, 111-128.

Menkhoff, L. and Schmeling, M. (2006) A prospect-theoretical interpretation of momentum returns, Economics Letters, 93, 360-366.

Menkhoff, L. and Schmidt, U. (2005) The use of trading strategies by fund managers: some first survey evidence, Applied Economics, 37, 1719-1730.

Menkhoff, L., Schmidt, U. and Brozynski, T. (2006) The impact of experience on risk taking, overconfidence, and herding of fund managers: complementary survey evidence, European Economic Review, 50, 1753-1766.

Menkhoff, L. and Taylor, M.P. (2007) The obstinate passion of foreign exchange professionals: technical analysis, Journal of Economic Literature, 45, 936-972.

Mulvey, J.M. and Kim, W.C. (2008) Active equity managers in the U.S.: do the best follow momentum strategies?, Journal of Portfolio Management, Winter 2008, 126-134.

Odean, T. (1998) Are investors reluctant to realize their losses?, Journal of Finance, 53, 17751798.

Rouwenhorst, K.G. (1998) International momentum strategies, Journal of Finance, 53, 267284.

Sadka, R. (2006) Momentum and post-earnings-announcement drift anomalies: the role of liquidity risk, Journal of Financial Economics, 80, 309-349.

Shefrin, H. and Statman, M. (1985) The disposition to sell winners too early and ride losers too long: theory and evidence, Journal of Finance, 40, 777-790.

Shiller, R.J. (2003) From efficient markets theory to behavioral finance, Journal of Economic Perspectives, 17, 83-104.

Taylor, M.P. and Allen, H. (1992) The use of technical analysis in the foreign exchange market, Journal of International Money and Finance, 11, 304-314.

Welch, I. (2000) Views of financial economists on the equity premium and on professional controversies, Journal of Business, 73, 501-537. 
TABLE 1. On the representativeness of responses

\begin{tabular}{lccccc}
\hline & US & GER & CH & ITA & THAI \\
Number of responses & 149 & 263 & 42 & 112 & 126 \\
Number of responding firms & 74 & 51 & 18 & 32 & 29 \\
Share of responding asset management firms & $29.6 \%$ & $77.3 \%$ & $29.0 \%$ & $58.2 \%$ & $93.5 \%$ \\
Ho: $_{0 \text { Structure of responding firms equals struc- }}$ & -1.213 & -0.669 & -0.385 & -0.403 & -0.136 \\
ture of the market $^{(a)}$ & $(0.225)$ & $(0.503)$ & $(0.700)$ & $(0.687)$ & $(0.892)$ \\
\hline
\end{tabular}

(a) Firms are characterized by assets under management. For Switzerland, however, the number of mutual funds offered is used as a proxy for the asset management industry. The figures given are the z-value of the MannWhitney U-test and the p-value in parenthesis.

TABLE 2. Information about responding fund managers

\begin{tabular}{lccccc}
\hline & US & GER & CH & ITA & THAI \\
Average age (in years) & 42.5 & 35.6 & 38.7 & 36.0 & 35.3 \\
Average experience (in years) & 14.0 & 7.4 & 10.6 & 8.8 & 7.0 \\
Academic education (in \% of total) & 81.8 & 86.8 & 86.8 & 93.5 & 96.0 \\
Senior position (in \% of total) ${ }^{(a)}$ & 84.8 & 68.0 & 92.9 & 83.3 & 61.9 \\
$\begin{array}{l}\text { Mutual fund managers } \\
\text { (vs. pension funds, etc. in \%) }\end{array}$ & 42.0 & 39.1 & 50.0 & 79.0 & 61.5 \\
$\begin{array}{l}\text { Equity fund managers } \\
\text { (vs. bond and money market funds in \%) }\end{array}$ & 64.8 & 73.9 & 77.8 & 53.4 & 44.7 \\
\hline
\end{tabular}

${ }^{(a)}$ Senior position is defined on the basis of the response categories of item (4) in the later Table 3 referring to the asset manager's current position in a company. Given the answering categories of Junior asset manager [1], Senior asset manager [2], Head of asset management team [3] and CIO / CEO [4], the figure here is the sum of the \%-shares of the last 3 categories. 


\section{FIGURE 1. The relevance of momentum trading}

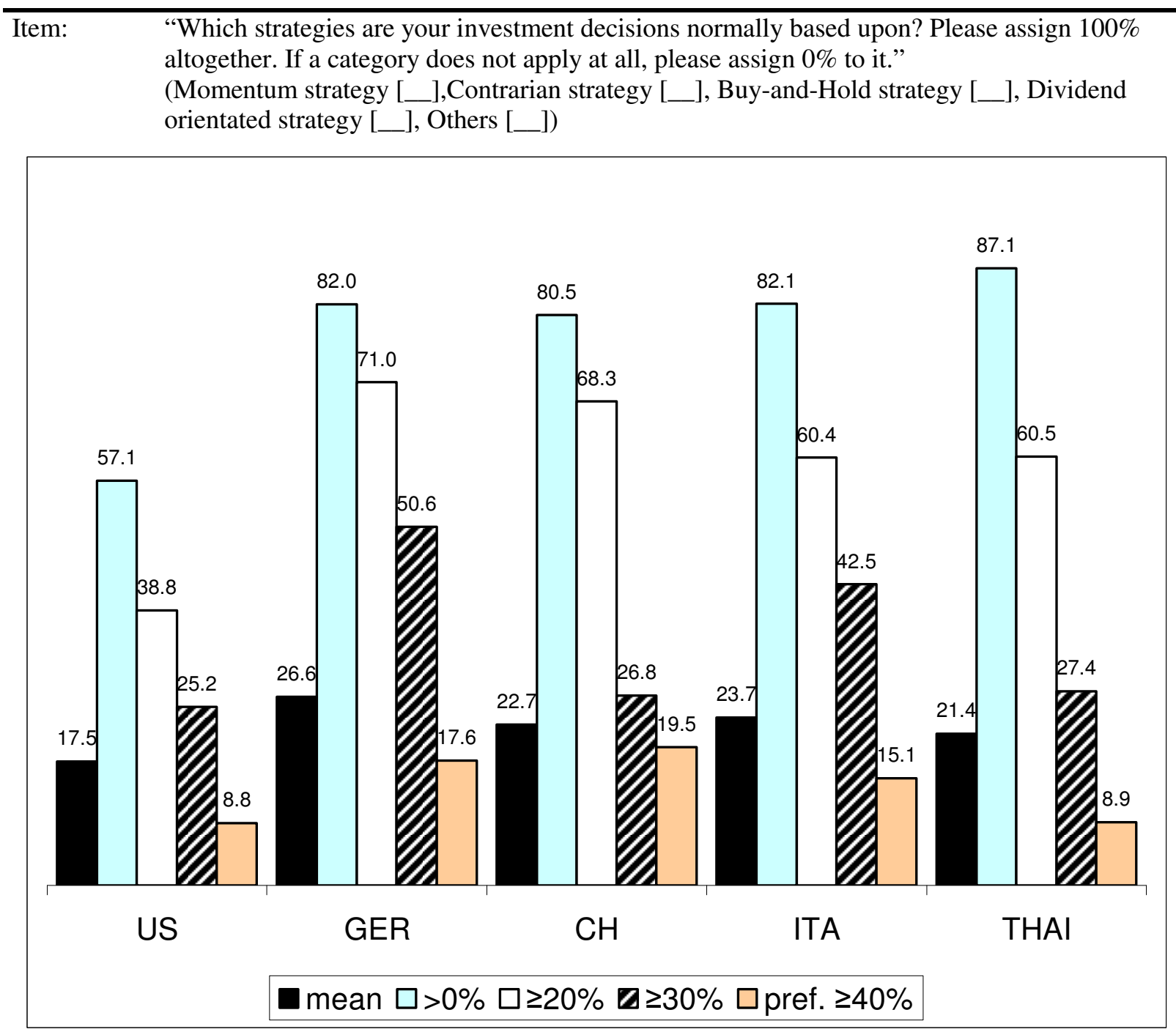

Note: This figure represents the relevance of the momentum strategy at different levels of intensity of use. The black bar gives the mean value, indicating for example that US fund managers give momentum trading a weight of $17.5 \%$ among strategies. The other bars give shares of fund managers, each fulfilling the criterion stated, i.e. give momentum trading a weight of more than $0 \%$, equal to or more than $20 \%$ or $30 \%$ respectively. The last category shows the share of fund managers who unanimously prefer the momentum strategy to all alternatives. This is defined by two criteria, i.e. a higher weight to momentum strategy than to all other categories plus a weight equal to or more than $40 \%$. 


\section{TABLE 3. Personal characteristics and the use of momentum trading}

(1) Item $^{(a)}$ : "How old are you?" ( $<31$ [1], 31-35 [2], 36-40 [3], 41-45 [4], 46-50 [5], > 50 [6] )

(2) Item ${ }^{(a): ~ " P r o f e s s i o n a l ~ e x p e r i e n c e ~ i n ~ a s s e t ~ m a n a g e m e n t ~(i n ~ y e a r s) " ~}$ ( $<4$ [1], 4-6 [2], 7-9 [3], 10-12 [4],13-15 [5], > 15 [1] )

(3) Item ${ }^{(a): ~ " E d u c a t i o n a l ~ l e v e l " ~}$ (Non-academic education [1], Academic education [3])

(4) Item ${ }^{(a)}$ : "Current position within your company" (Junior asset manager [1], Senior asset manager [2], Head of asset management team [3], CIO / CEO [4])

(5) $\mathrm{Item}^{(\mathrm{a})}$ : "Your personal responsibility for assets under management (in million of US dollar or euro)" (< 50 [1], 50-250 [2], 250-1000 [3], 1000-2500 [4], 2500-10000 [5], > 10000 [6] )

(6) Item ${ }^{(a)}$ : "Your company's total volume of assets under management (in billion of US dollar or euro)" $(<5$ [1], 5-10 [2], 10-20 [3], 20-50 [4], 50-100 [5], > 100 [6] )

\begin{tabular}{|c|c|c|c|c|c|}
\hline & \multicolumn{5}{|c|}{ Descriptive statistics $^{(b)}$} \\
\hline & US & GER & $\mathrm{CH}$ & ITA & THAI \\
\hline & MT others ${ }^{(\mathrm{c})}$ & MT others & MT others & MT others & MT others \\
\hline (1) Higher age ${ }^{(d)}$ & $\begin{array}{c}3.64 \quad 3.86 \\
-0.767 \\
(0.443)\end{array}$ & $\begin{array}{c}2.45 \quad 2.58 \\
-1.243 \\
(0.214)\end{array}$ & $\begin{array}{cc}3.08 & 3.10 \\
-0.214 \\
(0.831)\end{array}$ & $\begin{array}{cc}2.69 & 2.49 \\
-0.617 \\
(0.537)\end{array}$ & $\begin{array}{c}2.17 \quad 2.57 \\
-1.932^{*} \\
(0.053)\end{array}$ \\
\hline (2) More experience ${ }^{(d)}$ & $\begin{array}{cc}4.36 \quad 4.56 \\
-0.578 \\
(0.563)\end{array}$ & $\begin{array}{c}2.62 \quad 2.80 \\
-1.418 \\
(0.156)\end{array}$ & $\begin{array}{cc}3.50 & 3.72 \\
-0.350 \\
(0.726)\end{array}$ & $\begin{array}{cc}3.02 & 3.23 \\
-0.979 \\
(0.327)\end{array}$ & $\begin{array}{cc}2.72 \quad 2.67 \\
-0.214 \\
(0.831)\end{array}$ \\
\hline (3) Better education ${ }^{(d)}$ & $\begin{array}{cc}2.57 & 2.66 \\
-0.628 \\
(0.530)\end{array}$ & $\begin{array}{cc}2.68 & 2.80 \\
-1.331 \\
(0.183)\end{array}$ & $\begin{array}{cc}2.80 & 2.71 \\
-0.340 \\
(0.734)\end{array}$ & $\begin{array}{cc}2.91 & 2.83 \\
-0.843 \\
(0.399)\end{array}$ & $\begin{array}{cc}2.94 & 2.91 \\
-0.431 \\
(0.666)\end{array}$ \\
\hline (4) More senior position ${ }^{(d)}$ & $\begin{array}{cc}2.55 & 2.36 \\
-0.971 \\
(0.332)\end{array}$ & $\begin{array}{c}1.88 \quad 2.03 \\
-1.737^{*} \\
(0.082)\end{array}$ & $\begin{array}{cc}2.67 \quad 2.50 \\
-0.380 \\
(0.704)\end{array}$ & $\begin{array}{cc}2.44 & 2.53 \\
-0.449 \\
(0.653)\end{array}$ & $\begin{array}{cc}1.86 \quad 1.82 \\
-0.334 \\
(0.739)\end{array}$ \\
\hline (5) Volume personal resp. ${ }^{\text {(d) }}$ & $\begin{array}{cc}3.69 & 4.05 \\
-0.918 \\
(0.359)\end{array}$ & $\begin{array}{cc}3.29 & 3.59 \\
-1.599 \\
(0.110)\end{array}$ & $\begin{array}{cc}3.00 & 3.14 \\
-0.031 \\
(0.975)\end{array}$ & $\begin{array}{cc}3.22 & 3.36 \\
-0.671 \\
(0.502)\end{array}$ & $\begin{array}{cc}3.17 & 3.17 \\
-0.015 \\
(0.988)\end{array}$ \\
\hline (6) Volume company ${ }^{(\mathrm{d})}$ & $\begin{array}{cc}3.69 & 3.74 \\
-0.073 \\
(0.942)\end{array}$ & $\begin{array}{cc}3.81 & 4.29 \\
-2.105 * * \\
(0.035)\end{array}$ & $\begin{array}{cc}4.58 \quad & 4.79 \\
-1.020 \\
(0.307)\end{array}$ & $\begin{array}{cc}3.09 & 3.00 \\
-0.378 \\
(0.705)\end{array}$ & $\begin{array}{cc}2.60 & 2.49 \\
-0.546 \\
(0.585)\end{array}$ \\
\hline
\end{tabular}

(a) Response categories in parenthesis, encodings in [].

(b) Stars refer to level of significance: ${ }^{*} 10 \%,{ }^{* *} 5 \%,{ }^{* * *} 1 \%$.

(c) Asset managers belong to the group "MT", i.e. momentum traders, if they give the momentum strategy a weight of at least 30 per cent (see Figure 1 above on the exact question). "Others" are all other responding asset managers.

(d) Table gives the mean values for responding momentum traders (MT) and others. The figure in each of the last lines is the $\mathrm{z}$-value of the Mann-Whitney U-test with the respective p-value in parenthesis. 


\section{TABLE 4. Overconfidence and the use of momentum trading}

(1) Item ${ }^{(a)}$ : "How do you assess your achievement in asset management - compared to other asset manager's achievement in the same investment segment?"

(much better [1], ..., much worse [7])

(2) Item ${ }^{(a)}$ : "Most of the published business news does not surprise me at all."

(complete approval [1], ..., complete contradiction [6])

(3) Item ${ }^{(a)}$ : "Please estimate the development of the EuroSTOXX 50 and the Dow Jones within the next month. Please forecast the performance of the respective index with a probability of 90\%."

(Today's level, expected minimum level, expected maximum level.)

\begin{tabular}{|c|c|c|c|c|c|}
\hline & \multicolumn{5}{|c|}{ Descriptive statistics $^{(\mathrm{b})}$} \\
\hline & $\begin{array}{c}\text { US } \\
\text { MT others }\end{array}$ & $\begin{array}{c}\text { GER } \\
\text { MT others }\end{array}$ & $\begin{array}{c}\text { CH } \\
\text { MT others }\end{array}$ & $\begin{array}{c}\text { ITA } \\
\text { MT others }\end{array}$ & $\begin{array}{c}\text { THAI } \\
\text { MT others }\end{array}$ \\
\hline $\begin{array}{l}\text { (1) Comparatively } \\
\text { worse achievement }\end{array}$ & $\begin{array}{cc}2.61 & 2.71 \\
-0.787 \\
(0.432)\end{array}$ & $\begin{array}{c}3.25 \quad 2.96 \\
-2.330^{* * *} \\
(0.020)\end{array}$ & $\begin{array}{c}3.18 \quad 2.96 \\
-0.297 \\
(0.766)\end{array}$ & $\begin{array}{cc}3.02 & 2.83 \\
-1.062 \\
(0.288)\end{array}$ & $\begin{array}{c}3.06 \quad 3.18 \\
-0.839 \\
(0.402)\end{array}$ \\
\hline (2) News do not surprise & $\begin{array}{l}3.11 \quad 3.14 \\
-0.068 \\
(0.946)\end{array}$ & $\begin{array}{cc}3.30 & 3.17 \\
-0.791 \\
(0.429)\end{array}$ & $\begin{array}{c}3.46 \quad 2.89 \\
-1.199 \\
(0.231)\end{array}$ & $\begin{array}{l}3.50 \quad 3.45 \\
-0.519 \\
(0.604)\end{array}$ & $\begin{array}{c}3.06 \quad 3.16 \\
-0.400 \\
(0.689)\end{array}$ \\
\hline $\begin{array}{l}\text { (3) } 90 \% \text { width }^{(\mathrm{c})} \text { of index fore- } \\
\text { cast in percent: } \\
\text { - EuroSTOXX } 50\end{array}$ & $\begin{array}{l}22.22 \quad 25.83 \\
-0.151 \\
(0.880)\end{array}$ & $\begin{array}{l}20.80 \quad 24.02 \\
-0.309 \\
(0.758)\end{array}$ & $\begin{array}{c}16.1427 .68 \\
-0.597 \\
(0.551)\end{array}$ & $\begin{array}{l}10.2110 .04 \\
-0.112 \\
(0.911)\end{array}$ & $\begin{array}{l}12.5417 .31 \\
-1.079 \\
(0.281)\end{array}$ \\
\hline - Dow Jones & $\begin{array}{c}15.26 \quad 18.43 \\
-0.330 \\
(0.741)\end{array}$ & $\begin{array}{cc}14.39 \quad 17.29 \\
-0.348 \\
(0.728)\end{array}$ & $\begin{array}{c}10.44 \quad 22.57 \\
-0.330 \\
(0.741)\end{array}$ & $\begin{array}{c}9.76 \quad 8.23 \\
-0.869 \\
(0.385)\end{array}$ & $\begin{array}{c}12.06 \quad 12.93 \\
-0.478 \\
(0.633)\end{array}$ \\
\hline
\end{tabular}

(a) Response categories in parenthesis, encodings in [ ].

(b) Table gives the mean values for responding momentum traders (MT) and others. The figure in each of the last lines is the $\mathrm{z}$-value of the Mann-Whitney U-test with the respective p-value in parenthesis. Stars refer to level of significance: $\quad * 10 \%,{ }^{* *} 5 \%,{ }^{* * *} 1 \%$.

(c) The width is calculated as (expected maximum level minus expected minimum level) / average expected index level. 
TABLE 5. Beliefs about asset managers' behavior and the use of momentum trading

(1) Item ${ }^{(\text {a) }}$ : "People are not machines; thus security prices are clearly more determined by psychological influences than by fundamentals."

(2) Item $^{(a)}$ : "Herding is observable amongst professional asset managers."

(3) Item ${ }^{(a)}$ : "Asset Managers often disregard some information, if it does not complement their opinion."

\begin{tabular}{|c|c|c|c|c|c|}
\hline & \multicolumn{5}{|c|}{ Descriptive statistics $^{(\mathrm{b})}$} \\
\hline & US & GER & $\mathrm{CH}$ & ITA & THAI \\
\hline & MT others & MT others & MT others & MT others & MT others \\
\hline $\begin{array}{l}\text { (1) Dominance of psychological } \\
\text { influences on prices }\end{array}$ & $\begin{array}{cc}2.87 & 3.36 \\
-1.875^{*} \\
(0.061)\end{array}$ & $\begin{array}{cc}2.55 & 3.04 \\
-3.112 * * * \\
(0,002)\end{array}$ & $\begin{array}{cc}2.42 & 2.83 \\
-1.058 \\
(0.290)\end{array}$ & $\begin{array}{cc}2.94 & 2.98 \\
-0.016 \\
(0.987)\end{array}$ & $\begin{array}{cc}3.14 & 3.36 \\
-0.821 \\
(0.411)\end{array}$ \\
\hline (2) Herding amongst professionals & $\begin{array}{cc}2.23 \quad 2.22 \\
-0.339 \\
(0.735)\end{array}$ & $\begin{array}{cc}2.18 & 2.47 \\
-1.392 \\
(0.164)\end{array}$ & $\begin{array}{cc}2.42 & 2.14 \\
-1.074 \\
(0.283)\end{array}$ & $\begin{array}{cc}2.54 & 2.46 \\
-0.758 \\
(0.448)\end{array}$ & $\begin{array}{cc}2.86 & 2.89 \\
-0.047 \\
(0.963)\end{array}$ \\
\hline (3) Objective information & $\begin{array}{cc}2.26 \quad 2.44 \\
-0.515 \\
(0.607)\end{array}$ & $\begin{array}{c}3.18 \quad 3.51 \\
-1.863 * \\
(0.063)\end{array}$ & $\begin{array}{c}2.17 \quad 2.97 \\
-1.881^{*} \\
(0.060)\end{array}$ & $\begin{array}{cc}3.40 & 3.36 \\
-0.169 \\
(0.866)\end{array}$ & $\begin{array}{cc}3.50 \quad 3.71 \\
-0.678 \\
(0.498)\end{array}$ \\
\hline
\end{tabular}

(a) There are 6 answering categories, ranging from "agree completely" (encoded as 1) to "disagree completely" (encoded as 6). Thus, a mean of 3.5 or less indicates rather approval to the statement.

(b) Table gives the mean values for responding momentum traders (MT) and others. The figure in each of the last lines is the $\mathrm{z}$-value of the Mann-Whitney U-test with the respective p-value in parenthesis. Stars refer to level of significance: ${ }^{*} 10 \%,{ }^{* *} 5 \%,{ }^{* * *} 1 \%$.

\section{TABLE 6. Short horizons and the use of momentum trading}

(1) Item: "What is your personal forecasting horizon when making investment decisions?" (days [2], weeks [3], 2-6 months [4], 6-12 months [5], years [6])

(2) Item ${ }^{(a)}$ : "I generally follow the trend."

(3) Item ${ }^{(a)}$ : "I often trade too much, as my clients demand short-term performance."

\begin{tabular}{|c|c|c|c|c|c|}
\hline & \multicolumn{5}{|c|}{ Descriptive statistics $^{(\mathrm{b})}$} \\
\hline & US & GER & $\mathrm{CH}$ & ITA & THAI \\
\hline & MT others & MT others & MT others & MT others & MT others \\
\hline (1) Forecasting horizon & $\begin{array}{cc}4.38 & 5.35 \\
-5.578 * * * \\
(0.000)\end{array}$ & $\begin{array}{c}3.96 \quad 4.43 \\
-4.93^{* * * *} \\
(0.000)\end{array}$ & $\begin{array}{c}4.36 \quad 5.00 \\
-2.291 * * \\
(0.022)\end{array}$ & $\begin{array}{c}4.13 \quad 4.63 \\
-3.285^{* * * *} \\
(0.001)\end{array}$ & $\begin{array}{c}3.113 .47 \\
-2.731 * * * \\
(0.006)\end{array}$ \\
\hline (2) Follow the trend & $\begin{array}{c}3.74 \quad 4.65 \\
-3.804 * * * \\
(0.000)\end{array}$ & $\begin{array}{c}3.39 \quad 3.97 \\
-4.039 * * * \\
(0.000)\end{array}$ & $\begin{array}{cc}3.82 & 4.07 \\
-0.583 \\
(0.560)\end{array}$ & $\begin{array}{cc}3.39 & 4.35 \\
-3.986 * * * \\
(0.000)\end{array}$ & $\begin{array}{c}3.03 \quad 3.44 \\
-1.666^{*} \\
(0.096)\end{array}$ \\
\hline (3) Higher trading activity & $\begin{array}{c}4.61 \quad 5.02 \\
-1.734^{*} \\
(0.083)\end{array}$ & $\begin{array}{cc}4.60 & 4.93 \\
-2.244 * * \\
(0.025)\end{array}$ & $\begin{array}{cc}4.36 & 5.00 \\
-1.422 \\
(0.155)\end{array}$ & $\begin{array}{cc}4.28 & 5.05 \\
-3.422 * * * \\
(0.001)\end{array}$ & $\begin{array}{c}4.11 \quad 4.61 \\
-1.989 * * \\
(0.047)\end{array}$ \\
\hline
\end{tabular}

(a) There are 6 answering categories, ranging from "agree completely" (encoded as 1) to "disagree completely" (encoded as 6). Thus, a mean of 3.5 or less indicates rather approval to the statement.

(b) Table gives the mean values for responding momentum traders (MT) and others. The figure in each of the last lines is the z-value of the Mann-Whitney U-test with the respective p-value in parenthesis. Stars refer to level of significance: ${ }^{*} 10 \%,{ }^{* *} 5 \%,{ }^{* * *} 1 \%$. 
FIGURE 2. The share of momentum traders at individuals' preferred forecasting horizon

Item: "What is your personal forecasting horizon when making investment decisions?" (days [2], weeks [3], 2-6 months [4], 6-12 months [5], years [6] )

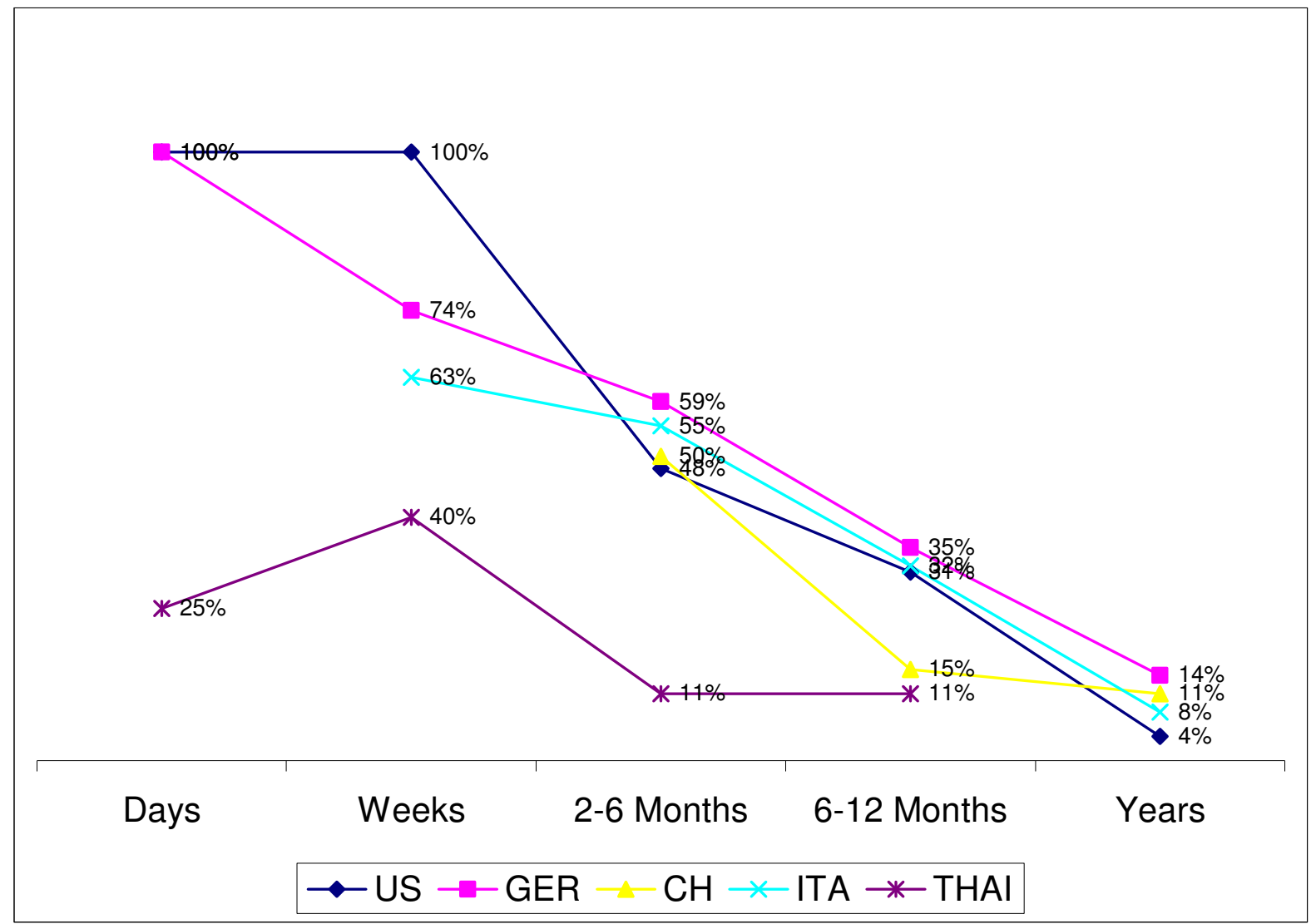

Note: This figure gives all shares, independent of the number of underlying cases, which may be very small for some categories. Raw numbers for the US are, for example: 3 momentum traders of 3 fund managers with a horizon of days, 1 of 1 for weeks, 15 of 31, 18 of 58 and 2 of 56, respectively. 


\section{TABLE 7. Risk aversion and the use of momentum trading}

(1) Item: "Imagine someone offers you a bet and the odds are fifty-fifty. You will have to pay 1000 Euros from your personal account, if you lose. What would be the minimum amount you would expect to win to lure you into accepting the bet?" (minimum amount in multiple of 1000 Euros)

(2) Item ${ }^{(a)}$ : "In respect of professional investment decisions, I mostly act..."

(3) Item ${ }^{(b)}$ : "I prefer to take profits instead of cutting losses, when I am confronted with unexpected liquidity demands."

(4) Item $^{(b)}$ : "In case of loss position in my portfolio I generally wait for a price rebound instead of selling those securities."

(1) Bet ${ }^{(d)}$

(2) Risk aversion

(3) Prefer to take profits

(4) Wait for a price rebound

\begin{tabular}{|c|c|c|c|c|}
\hline \multicolumn{5}{|c|}{ Descriptive statistics $^{(c)}$} \\
\hline US & GER & $\mathrm{CH}$ & ITA & THAI \\
\hline MT others & MT others & MT others & MT others & MT others \\
\hline $\begin{array}{c}2.00 \quad 2.00 \\
0.330 \\
(0.566)\end{array}$ & $\begin{array}{cc}1.50 & 2.00 \\
0.164 \\
(0.686)\end{array}$ & $\begin{array}{c}2.05 \quad 2.00 \\
0.097 \\
(0.755)\end{array}$ & $\begin{array}{c}2.00 \quad 3.00 \\
1.530 \\
(0.216)\end{array}$ & $\begin{array}{c}2.00 \quad 2.00 \\
1.134 \\
(0.287)\end{array}$ \\
\hline $\begin{array}{c}4.03 \quad 3.38 \\
-3.079 * * * \\
(0.002)\end{array}$ & $\begin{array}{cc}3.54 & 3.47 \\
-0.148 \\
(0.882)\end{array}$ & $\begin{array}{c}4.18 \quad 3.38 \\
-2.121^{* *} \\
(0.034)\end{array}$ & $\begin{array}{cc}3.59 & 3.52 \\
-0.306 \\
(0.759)\end{array}$ & $\begin{array}{cc}3.17 & 3.19 \\
-0.494 \\
(0.621)\end{array}$ \\
\hline $\begin{array}{c}4.10 \quad 3.68 \\
-1.867^{*} \\
(0.062)\end{array}$ & $\begin{array}{cc}3.93 & 4.41 \\
-2.733 * * * \\
(0.006)\end{array}$ & $\begin{array}{cc}4.27 \quad 4.21 \\
-0.489 \\
(0.625)\end{array}$ & $\begin{array}{c}3.72 \quad 3.95 \\
-0.787 \\
(0.432)\end{array}$ & $\begin{array}{cc}3.19 \quad 3.08 \\
-0.093 \\
(0.926)\end{array}$ \\
\hline $\begin{array}{cc}4.55 \quad 4.09 \\
-1.776^{*} \\
(0.076)\end{array}$ & $\begin{array}{cc}4.50 & 4.65 \\
-1.204 \\
(0.229)\end{array}$ & $\begin{array}{cc}4.27 \quad 4.32 \\
-0.328 \\
(0.743)\end{array}$ & $\begin{array}{cc}4.26 \quad 4.19 \\
-0.096 \\
(0.923)\end{array}$ & $\begin{array}{c}3.83 \quad 3.58 \\
-1.282 \\
(0.200)\end{array}$ \\
\hline
\end{tabular}

(a) There are 6 answering categories, ranging from "very risk averse" (encoded as 1) to "little risk averse" (encoded as 6). Thus, a mean of 3.5 or less indicates rather approval to the statement.

(b) There are 6 answering categories, ranging from "complete approval" (encoded as 1) to "complete contradiction" (encoded as 6). Thus, a mean of 3.5 or less indicates rather approval to the statement.

(c) Table gives the mean values for responding momentum traders (MT) and others. The figure in each of the last lines is the z-value of the Mann-Whitney U-test with the respective p-value in parenthesis. Stars refer to level of significance: ${ }^{*} 10 \%,{ }^{* *} 5 \%,{ }^{* * *} 1 \%$.

(d) Median values are given in thousand Euros. In the US all figures are in US-Dollars. In Thailand the amount to be possibly lost is 5,000 Baht (about 100 Euros or US-Dollars) to compensate for the lower income level (GDP per capita was roughly ten percent of the US value). The figure in each of the last lines is the chi-squarevalue of the Kruskal-Wallis-test with the respective p-value in parenthesis. 
TABLE 8. Characteristics of momentum traders

\begin{tabular}{|c|c|c|c|c|c|}
\hline & $\mathrm{US}^{(\mathrm{c})}$ & GER & $\mathrm{CH}$ & ITA & THAI \\
\hline $\begin{array}{l}\text { (1) Dominance of psychological } \\
\text { influences on prices }\end{array}$ & $\begin{array}{l}-0.082 \\
-0.691\end{array}$ & $\begin{array}{l}-0.201 \\
-2.610 * * *\end{array}$ & $\begin{array}{l}-0.339 \\
-1.225\end{array}$ & $\begin{array}{l}0.086 \\
0.837\end{array}$ & $\begin{array}{l}-0.010 \\
-0.091\end{array}$ \\
\hline (2) Objective information ${ }^{\text {(a) }}$ & $\begin{array}{l}0.018 \\
0.125\end{array}$ & $\begin{array}{l}-0.003 \\
-0.038\end{array}$ & $\begin{array}{l}-0.924 \\
-2.303 * *\end{array}$ & $\begin{array}{l}0.081 \\
0.865\end{array}$ & $\begin{array}{l}-0.053 \\
-0.455\end{array}$ \\
\hline (3) Forecasting horizon ${ }^{(b)}$ & $\begin{array}{l}-0.769 \\
-4.440 * * *\end{array}$ & $\begin{array}{l}-0.553 \\
-4.567 * * *\end{array}$ & $\begin{array}{l}-1.005 \\
-1.882 *\end{array}$ & $\begin{array}{l}-0.212 \\
-1.466\end{array}$ & $\begin{array}{l}-0.523 \\
-2.561 * *\end{array}$ \\
\hline (4) Follow the trend ${ }^{(a)}$ & $\begin{array}{l}-0.168 \\
-1.427\end{array}$ & $\begin{array}{l}-0.184 \\
-2.585 * * *\end{array}$ & $\begin{array}{l}0.327 \\
0.913\end{array}$ & $\begin{array}{l}-0.114 \\
-1.249\end{array}$ & $\begin{array}{l}-0.185 \\
-1.551\end{array}$ \\
\hline (5) Higher trading activity ${ }^{\text {(a) }}$ & $\begin{array}{l}-0.008 \\
-0.076\end{array}$ & $\begin{array}{l}0.056 \\
0.743\end{array}$ & $\begin{array}{l}-0.444 \\
-1.373\end{array}$ & $\begin{array}{l}-0.117 \\
-1.035\end{array}$ & $\begin{array}{l}-0.107 \\
-1.037\end{array}$ \\
\hline (6) Risk aversion ${ }^{\text {(a) }}$ & $\begin{array}{l}0.146 \\
1.454\end{array}$ & $\begin{array}{l}0.182 \\
2.090^{* * *}\end{array}$ & $\begin{array}{l}0.995 \\
2.721 * * *\end{array}$ & $\begin{array}{l}0.098 \\
1.226\end{array}$ & $\begin{array}{l}-0.045 \\
-0.336\end{array}$ \\
\hline McFadden $\mathrm{R}^{2}$ & 0.260 & 0.147 & 0.456 & 0.078 & 0.097 \\
\hline
\end{tabular}

Note: This table builds on the earlier tables. It explains in a multivariate Probit regression whether traders are "momentum traders" (coded as 1) or "others". The explanatory variables are taken from earlier Tables 5, 6 and 7 and are explained there.

(a) There are 6 answering categories, ranging from "complete approval" (coded as 1$)$ to "complete contradiction" (coded as 6).

(b) Answers range from days to years and are coded between 2 and 6.

(c) This table reports coefficients and corresponding z-values of a Probit regression for analyzing the influence of the listed variables (1-6) on momentum trading. Stars refer to level of significance: ${ }^{*} 10 \%,{ }^{* *} 5 \%,{ }^{* * *} 1 \%$. 


\section{APPENDIX 1. Remuneration criteria and the use of momentum trading}

"If you receive a performance-based remuneration, which criteria determine the size of that bonus?"

(1) Item ${ }^{(a)}$ : "Absolute fund performance"

(2) Item ${ }^{(a): ~ " R e l a t i v e ~ f u n d ~ p e r f o r m a n c e " ~}$

(3) Item ${ }^{(a)}$ : "Business development of the investment company"

(4) Item ${ }^{(a)}$ : "Subjective assessment by superiors and colleagues"

\begin{tabular}{|c|c|c|c|c|c|}
\hline & \multicolumn{5}{|c|}{ Descriptive statistics $^{(b)}$} \\
\hline & US & GER & $\mathrm{CH}$ & ITA & THAI \\
\hline & MT others ${ }^{(c)}$ & MT others & MT others & MT others & MT others \\
\hline $\begin{array}{l}\text { (1) Absolute } \\
\text { performance }^{(d)}\end{array}$ & $\begin{array}{cc}4.15 \quad 4.34 \\
-0.483 \\
(0.629)\end{array}$ & $\begin{array}{c}4.09 \quad 4.20 \\
-0.565 \\
(0.572)\end{array}$ & $\begin{array}{cc}3.10 & 3.92 \\
-1.344 \\
(0.179)\end{array}$ & $\begin{array}{c}3.62 \quad 3.44 \\
-0.464 \\
(0.642)\end{array}$ & $\begin{array}{c}2.97 \quad 2.90 \\
-0.132 \\
(0.895)\end{array}$ \\
\hline $\begin{array}{l}\text { (2) Relative } \\
\text { performance }^{(d)}\end{array}$ & $\begin{array}{c}2.14 \quad 2.42 \\
-1.305 \\
(0.192)\end{array}$ & $\begin{array}{c}2.59 \quad 2.38 \\
-1.459 \\
(0.144)\end{array}$ & $\begin{array}{c}2.45 \quad 2.48 \\
-0.267 \\
(0.789)\end{array}$ & $\begin{array}{c}1.66 \quad 1.92 \\
-1.087 \\
(0.277)\end{array}$ & $\begin{array}{cc}2.47 & 2.41 \\
-0.164 \\
(0.870)\end{array}$ \\
\hline $\begin{array}{l}\text { (3) Business } \\
\text { development }\end{array}$ & $\begin{array}{c}3.00 \quad 2.53 \\
-1.429 \\
(0.153)\end{array}$ & $\begin{array}{c}2.24 \quad 1.98 \\
-2.077 * * \\
(0.038)\end{array}$ & $\begin{array}{c}2.75 \quad 2.46 \\
0.000 \\
(1.000)\end{array}$ & $\begin{array}{c}2.74 \quad 2.98 \\
-0.925 \\
(0.355)\end{array}$ & $\begin{array}{c}2.94 \quad 3.28 \\
-1.286 \\
(0.198)\end{array}$ \\
\hline $\begin{array}{l}\text { (4) Subjective } \\
\text { assessment }\end{array}$ & $\begin{array}{cc}2.58 \quad 2.82 \\
-0.800 \\
(0.423)\end{array}$ & $\begin{array}{cc}2.46 & 2.40 \\
-0.464 \\
(0.643)\end{array}$ & $\begin{array}{c}2.33 \quad 2.77 \\
-1.540 \\
(0.124)\end{array}$ & $\begin{array}{cc}2.77 & 2.82 \\
-0.117 \\
(0.907)\end{array}$ & $\begin{array}{c}3.09 \quad 3.10 \\
-0.097 \\
(0.922)\end{array}$ \\
\hline
\end{tabular}

(a) There are 6 answering categories, ranging from "highest relevance" (coded as 1) to "no relevance" (coded as 6). Thus, a mean of 3.5 or less indicates rather approval to the statement.

(b) Stars refer to level of significance: ${ }^{*} 10 \%,{ }^{* *} 5 \%,{ }^{* * *} 1 \%$.

(c) Asset managers belong to the group "MT", i.e. momentum traders, if they give the momentum strategy a weight of at least 30 per cent (see Figure 2 above on the exact question). "Others" are all other responding asset managers.

(d) Table gives the mean values for responding momentum traders (MT) and others. The figure in the last line each is the z-value of the Mann-Whitney U-test with the respective p-value in parenthesis. 
APPENDIX 2. Characteristics of momentum traders

\begin{tabular}{lccccc}
\hline & US & GER & CH & ITA & THAI \\
(1) Dominance of psychological & -0.063 & -0.240 & -1.829 & 0.116 & 0.001 \\
$\quad$ influences on prices & -0.466 & $-2.994^{* * *}$ & $-2.022^{* *}$ & 1.086 & 0.005 \\
(2) Objective information & 0.009 & 0.002 & -3.708 & 0.067 & -0.034 \\
& 0.054 & 0.030 & $-2.312^{* *}$ & 0.691 & -0.241 \\
(3) Forecasting horizon & -1.062 & -0.482 & -1.039 & -0.301 & -0.534 \\
& $-4.431^{* * *}$ & $-3.475^{* * *}$ & $-1.645^{*}$ & $-1.898^{*}$ & $-2.427^{* *}$ \\
& -0.166 & -0.246 & 0.078 & -0.141 & -0.343 \\
(4) Follow the trend & -1.251 & $-3.015^{* * *}$ & 0.170 & -1.509 & $-2.229^{* *}$ \\
& 0.096 & 0.104 & -1.820 & -0.165 & -0.111 \\
(5) Higher trading activity & 0.779 & 1.227 & $-1.836^{*}$ & -1.403 & -0.877 \\
& 0.186 & 0.223 & 3.076 & 0.244 & 0.016 \\
(6) Risk aversion & $1.678^{*}$ & $2.268^{* *}$ & $2.557^{* *}$ & $2.296^{* *}$ & 0.101 \\
& 0.188 & -0.065 & -0.606 & 0.103 & 0.238 \\
(7) Prefer to take profits ${ }^{(b)}$ & $1.700^{*}$ & -0.994 & -1.255 & 1.136 & $2.030^{* *}$ \\
& $3 / 13$ & $3 / 21$ & $1 / 2$ & $1 / 1$ & $5 / 12$ \\
Relative share of significant $_{\text {firm dummy variables }}^{(\mathrm{c})}$ & & & & & \\
McFadden R $^{2}$ & 0.339 & 0.216 & 0.710 & 0.113 & 0.283 \\
\hline
\end{tabular}

Note: This table builds on the earlier Table 8. It explains in a multivariate Probit regression whether traders are "momentum traders" (coded as 1) or "others". The explanatory variables are taken from earlier Tables 5, 6 and 7 and are explained there.

(a) This table reports coefficients and corresponding $\mathrm{z}$-values of a Probit regression for analyzing the influence of the listed variables (1-7) (and dummy variables) on momentum trading. Stars refer to level of significance: ${ }^{*} 10 \%,{ }^{* *}$ $5 \%,{ }^{* * *} 1 \%$.

(b) This variable is considered for robustness purposes. Results are robust to its exclusion

(c) These variables are dummy variables if we know about a responding fund managers' firm and if there are at least three managers in this group. The value of "3/13" for the US means that we form dummies for 13 firms and that fund managers from three of these 13 firms show a significantly different behaviour from others. 